\title{
Determination of Central Corneal Thickness in Patients with Refractive Anomalies and Emmetropy
}

\author{
Mimoza Ismaili' ${ }^{1}$, Gazmend Kaçaniku' ${ }^{1}$, Kelmend Spahiu ${ }^{1}$, Gentian Hoxha ${ }^{1}$, \\ Наташа Наќева-Јаневска², Весна Димовска-Јорданова²
}

\begin{abstract}
${ }^{1}$ Department of Ophthalmology, Faculty of Medicine, University Clinical Center of Kosovo, Pristina, Republic of Kosovo
${ }^{2}$ Republic of Macedonia University “Saints Cyril and Methodius”, Skopje, Republic of Macedonia
\end{abstract}

Email: moxa_i@hotmail.com

How to cite this paper: Ismaili, M., Kaçaniku, G., Spahiu, K., Нохha, G., Наќева-Јаневска, H. and Димовска-Јорданова, В. (2019) Determination of Central Corneal Thickness in Patients with Refractive Anomalies and Emmetropy. Open Journal of Ophthalmology, 9, 35-46.

https://doi.org/10.4236/ojoph.2019.92005

Received: January 23, 2019

Accepted: March 11, 2019

Published: March 14, 2019

Copyright (๑) 2019 by author(s) and Scientific Research Publishing Inc. This work is licensed under the Creative Commons Attribution International License (CC BY 4.0).

http://creativecommons.org/licenses/by/4.0/

\section{(c) (i) Open Access}

\begin{abstract}
Aim: The purpose of this study was to compare measurements of CCT in emmetropia and patient with refractive anomalies. Methods: We represent a retrospective research which was conducted at the University Clinical Center of Kosovo (UCCK). In this study were included 80 patients, divided into two groups: test and a control group. Mean age was $(M=25.90, D S=7.16)$, men $(\mathrm{N}=41 \%$ or $51.3 \%)$ and women $(\mathrm{N}=39 \%$ or $48 \%)$. Results: Results show that there were no differences in the CCT, Hyperopic $(\mathrm{M}=545.21 \mathrm{DS}=$ 52.24), Myopic $(\mathrm{M}=547.90 \mathrm{DS}=47.93)$ and Emmetropic $(\mathrm{M}=550.75 \mathrm{DS}=$ 41.29). After measuring of the longitudinal axis and analyzing the data by means of Anova test, it appeared to be a significant difference between the analyzed groups, Hyperopic $(\mathrm{M}=21.99$, $\mathrm{DS}=1.27)$, Myopics $(\mathrm{M}=23.21$, DS $=1.24)$, Emmetropic $(M=22.36$, DS $=0.81)$. Results also revealed that there is correlation between the CCT and IOP, where increase CCT decreases IOP and vice versa $(r=-0.26, p=0.01)$. Conclusion: The results have shown that CCT is thinner in myopic but does not show correlation with hypermetropic and emmetropic. While during the measurement of central corneal thickness and eye tension it is found that there is a negative correlation between them. Keratometry has a negative correlation with CCT. While there was no correlation between CCT and age. Given the role of CCT in interpreting IOP values, it is recommended to perform a systematic CCT measurement in routine clinical practice, which would assist in the diagnosis of ocular hypertension.
\end{abstract}

\section{Keywords}

Corneal Thickness, Goldman Method, Keratometry, Pachymetry 


\section{Introduction}

The determination of corneal thickness has gained relevance in recent years, partly due to the growing interest in the continued use of contact lenses, refractive surgery, and the early identification of those who are at a higher risk of developing primary open angle glaucoma [1]. Due to the increasing popularity of correction of refractive defects by excimer laser, Central corneal thickness (CCT) has come to have higher prognostic significance for determination of the success of surgery and probable post-surgical complications [2]. Also, a thin cornea leads to underestimation of the intraocular pressure (IOP) whereas a thick cornea results in overestimation. Due to the relationship between central corneal thickness (CCT) and IOP, low CCT values may lead to a delay in the diagnosis and treatment of glaucoma which may in turn lead to visual impairment and blindness [2] [3]. Therefore knowledge of CCT can help to attribute the likelihood of disease progression and assigning the risk can change clinical management decisions to reach a personalized target pressure [4]. Empirical studies suggest a correction factor for applanation IOP readings of 0.19 to $1 \mathrm{~mm} \mathrm{Hg}$ per $10-\mu \mathrm{m}$ deviation from the average CCT [5]. Therefore, in individuals with thick corneas, the IOP measurement by using GAT may show falsely high readings and low readings for thin corneas [6]. A device called a tonometer is used to measure IOP. The instrument considered to be the "gold standard" by the ophthalmic community, and the focus of this study, is the Goldmann Applanation Tonometer ("GAT") [6]. The normal range of the intraocular pressure in human is $10-20 \mathrm{~mm} \mathrm{Hg}$. Therefore, in individuals with thick corneas, the IOP measurement by using, GAT may show falsely high readings and low readings for thin corneas [6]. The IOP measurement by applanation tonometry is based on the Imbert-Fick principle, which states that the required force of application of the sphere surface is equal to the pressure product within a fluid filled sphere and they are applanar [7]. Myopic eyes are associated with increased risk for glaucoma. Also, the corneas tended to be thinner in more myopic eyes [8].

Refractive errors are the most common ocular problem affecting all age groups [9]. In many cases, the results are inconclusive and at times, conflicting. The outcome and success rate of refractive surgical procedure rely on accuracy of pachymetry measurements [10]. The direct costs of these errors, which include correction by glasses, refractive surgeries and lens implantation, are high for societies with a high percentage of the afflicted individuals [11]. Refractive error occurs when there is failure of the eye to correctly focus rays of light from an object onto the retinal plane. The resultant image perceived by the individual is blurred, and refractive correction is required to see clearly. Refractive error can be divided into myopia (short or nearsightedness), hyperopia (long or far-sightedness) and astigmatism (irregularly curved cornea) [7]. Refractive errors are not preventable but can easily be treated with corrective eye glasses, contact lenses or in some cases, corrective surgery [12].

In this study have been researched the possible correlations between refractive 
anomalies, CCT, longitudinal axis of the eye (AL), IOP, and keratometry (K).

\section{Subjects and Methods}

This study is a retrospective study. It was conducted at the UCCK of the Republic of Kosovo in Prishtina. The study included 80 patients divided into the two groups: eyes with normal visual acuity (16), and eyes with anomaly refractive abnormalities (64), in a period of time from February 2016 to January 2018. Respondents with normal visual acuity were selected after a detailed preliminary examination. There were 80 participants in this research, of whom $(\mathrm{N}=41$ or $51.3 \%)$ were male and $(\mathrm{N}=39$ or $48.8 \%)$ were females. Average age was $(\mathrm{M}=$ 25.90, SD = 7.16).

Each individual signed an informed consent form prior to participation, after receiving information on the objective of the study.

\section{Statistical Analysis}

The data were represented by the mean \pm standard deviation (SD). The relationships between CCT, refractive error, keratometry, IOP and AL were tested using Pearson's correlation and multiple linear regression analysis. One eye from each participant was selected for the statistical analysis, using the following algorithm: the right eye was chosen where both were normal, otherwise the eye meeting the inclusion criteria was used.

\section{Study Design}

\subsection{Study Sample}

The study included a total of 80 patients who came to the clinic, as ambulatory cases with impaired vision symptoms, halos around bright lights, headaches, and haziness. The subjects were aged 18 to 38 , from urban and rural areas. After the initial examination they were included in this study. This number of patients was divided into the test group (64 participants) and the control group (16 participants).

Patients with the abovementioned symptoms were included in the test group, while the control group included emmetropia that did not have the abovementioned symptoms.

\subsection{Inclusion Criteria}

Patients with refractive anomalies who have not been diagnosed before; Patients with refractive anomalies between the age of 18 and 40 years old regardless gender; Patients with necessity for refractive anomalies correction, normal corneal topography, participants who had no ocular disease, participants who did not have eye surgery interventions.

\subsection{Exclusion Criteria}

Patients with glaucoma and previous corneal refractive surgery procedures; pa- 
tients who have already been corrected for refractive anomalies; presbyopic patients; patients with amblyopia, patients with corneal lesions, diabetes mellitus or other acute or chronic diseases possibly affecting the corneal thickness were excluded.

\subsection{Data Collection}

All subjects in the test group and in the control group were measured for the central corneal thickness by ultrasound pachymetry (USG) by trained ophthalmic technicians. The pachymetry measurement recorded for each eye was the average of 3 measurements taken per eye.

Ultrasonic pachymetry was performed in all patients under topical anesthesia with tetracaine (1\%), while vision acuity was examined by the Snellen chart. In the cases of refractive anomalies cycloplegic was used with 3 drops of $1 \%$ cyclopentolate (Cyclogyl) that were administered 5 minutes apart. After another 40 minutes subjective refraction was measured using an autorefractometer. During measurements, the subject was positioned with his or her chin in a cup and forehead against a headband. The respondents were asked to see the automated focused, focal target from the center of the cornea. The measurement was done automatically when the focus was reached. Refractive anomalies were calculated in diopters (D), the optical axis measurement using the B scan ultrasonography, and keratometry determination using a keratorefractometer. Three measurements were taken and the average values for vertical and horizontal corneal curvatures were recorded along the appropriate meridians. The average of both values was calculated as the AVK. IOP measurement was done with Goldmann applanation tonometry, anterior and posterior segment ophthalmic examination with slit lamp biomycroscopy, and fundus examination using indirect ophthalmoscopy with Volk Superfield lens 90D.

For the pachymetry, the subject was comfortably seated with the head upright and eyes in the primary position of gaze. The probe was sterilized with $70 \%$ alcohol and allowed to air-dry. The probe was, under topical anesthesia with tetracain (1\%), carefully placed in order perpendicularly and easily applied to the cornea. At least three readings were taken and the average was calculated as the measured CCT.

\section{Results}

There have been used correlation analyses to see relationship between variable and One Way Anova to compare groups.

There were 80 participants in this research, of whom $(\mathrm{N}=41 \%$ or $51.3 \%)$ were male and $(\mathrm{N}=39 \%$ or $48.8 \%)$ were females. Average age was $(\mathrm{M}=25.90$, $\mathrm{SD}=7.16$ ). This number of patients was divided into the test group (64 participants) and the control group (16 participants). In the test group there were 29 myopic and 35 hyperopic. While in the control group 16 emmetrop (see Table 1). 
Table 1. Demographic data.

\begin{tabular}{cccc}
\hline Variable & Test group & Control group & Total (\%) \\
\hline Respondents & 64 & 16 & $80(100 \%)$ \\
Male & 34 & 7 & $41(51.3 \%)$ \\
Female & 30 & 9 & $39(48.8 \%)$ \\
Myopic & 29 & - & $31(38.8 \%)$ \\
Hyperopic & 35 & - & $33(41.3 \%)$ \\
Emmetropic & - & 16 & $16(20.0 \%)$ \\
\hline
\end{tabular}

To understand better development of different ocular parameters of the eye and their interaction we have seen their descriptive value see Table 2.

Descriptive statistics such as the age, average corneal curvature, Goldmann applanation tonometry, visual acuity and central corneal thickness are presented in Table 2.

The lowest CCT is (Min = 295.0), while the highest level of cornea thickness is $(\operatorname{Max}=643.0)$. Also it was determined CCT and other ocular parameters, mean of CCT was $(\mathrm{M}=547.21, \mathrm{SD}=48.93), \mathrm{Km}$ was $(\mathrm{M}=42.38, \mathrm{SD}=1.97)$. Respondents reported different value of IOP, when lower level of it was $($ Min $=9.00)$ and higher levels or maximum was $(\operatorname{Max}=29.00)$. On the other hand mean of IOP in all respondents was $(M=15.05, S D=3.99)$, (Table 2).

There is a negative correlation between CCT and AVK $(r=-0.24, p=0.03)$, which shows us that increase of CCT is associated with decrease of AVK. On the other hand, has positive correlation between AL and AVK $(r=0.20, p=0.04)$, which means increase of AL in associated with increase of AVK. Same times don't have correlation between AL and IOP $(r=-0.09, p=n s)$. These results showed also that there was a negative correlation between CCT and IOP $(\mathrm{r}=$ $-0.26, \mathrm{p}=0.01$ ) (see Table 3 ).

When we analyzed the refractive anomalies, CCT, AL, IOP, our results showed that there was a negative correlation between participants with myopias and the CCT $(r=-0.41, p=0.01)$, which means that increase of CCT is associated with decrease of myopias to participants. At the same time we analyzed the correlation of CCT with hyperopic participant, and we found that there was no correlation between them $(r=0.02, p=0.91)$ as well as no correlation between CCT and emmetrop participants, $(r=-0.22, p=0.44)$. Other ocular parameters showed different correlation. There was positive correlation IOP and myopias $(r=0.46, p=0.01)$ and negative correlation between emmetropic respondents and IOP $(r=-0.58, p=0.05)$. Our results show a positive correlation between myopias respondents and visual acuity $(r=0.32, p=0.05)$. Also visual acuity has positive correlation with emmetropic respondents $(r=0.58, p=0.03)$, see Table 4.

In tend to understand interaction between different biometric parameters, regression analysis was applied.

Reported results found that CCT is negative predictor on IOP $(\beta=-0.26, \mathrm{p}=$ 
Table 2. Descriptive data.

\begin{tabular}{ccccc}
\hline Measured variables & Min & Max & Mean & SD \\
\hline VA (decimal) & 0.00 & 9.00 & 0.85 & 1.28 \\
IOP $(\mathrm{mm} \mathrm{Hg})$ & 9.00 & 29.00 & 15.05 & 3.99 \\
CCT $(\mu \mathrm{m})$ & 295.00 & 643.00 & 547.21 & 48.39 \\
AVK $(\mathrm{D})$ & 37.96 & 37.96 & 42.38 & 1.97 \\
AL $(\mathrm{mm})$ & 19.43 & 25.65 & 22.50 & 1.27 \\
\hline
\end{tabular}

(VA) Visual acuity, (IOP) Intraocular pressure, (CCT) Central corneal thickness, (AVK) Average corneal curvature, (AL) Axial length.

Table 3. Pearson correlation analyze of ocular parameter.

\begin{tabular}{ccccc}
\hline Variable & CCT & AVK & V. Acuity & IOP $(\mathrm{mm})$ \\
\hline CCT $(\mu \mathrm{m})$ & & & & \\
AVK (D) & $-0.24^{*}$ & & & \\
VA (decimal) & 0.11 & 0.09 & & \\
IOP (mm Hg) & $-0.26^{*}$ & -0.03 & -0.08 & -0.09 \\
AL (mm) & 0.04 & $0.20^{*}$ & 0.11 & \\
\hline
\end{tabular}

$p=0.02, p=0.05$ Correlations between central corneal thickness and other biometric parameters are presented.

Table 4. Correlation between refractive anomalies and other biometric parameters of eye.

\begin{tabular}{cccc}
\hline Variable & Hyperopic (diopters) & Myopic (diopters) & Emmetropic \\
\hline CCT $(\mu \mathrm{m})$ & -0.02 & $-0.41^{*}$ & -0.22 \\
AVK (D) & -0.05 & 0.24 & 0.28 \\
VA (decimal) & -0.06 & $0.32^{\star}$ & $0.58^{\star}$ \\
IOP (mm Hg) & 0.24 & $0.46^{*}$ & $-0.54^{*}$ \\
AL (mm) & 0.02 & -0.27 & -0.19 \\
\hline
\end{tabular}

$\mathrm{p}=0.01$

$0.01)$, but CCT did not have effect on VA $(\beta=-0.11, \mathrm{p}=0.33)$ (see Table 5).

In the follow-up of the various analyses we have looked at the difference between different biometric parameter and CCT. The results showed that there was no difference between the refractive anomalies and the CCT by rejecting our hypothesis $\mathrm{F}(2,78)=0.09, \mathrm{p}=\mathrm{ns}$ (using the One Way Anova analysis). From the mean value of CCT was as follows; for myopia $(\mathrm{CCT}=547.90$, DS $=47.93)$, for hyperopia $(\mathrm{CCT}=545.21, \mathrm{DS}=52.24)$ and emmetropic $(\mathrm{CCT}=550.75, \mathrm{DS}=$ 41.29).

In Figure 1, are described differences in IOP between different age group. When the mean IOP was analyzed regarding the age groups, it was found that the participants between $16-20$ years have $(M=13.84), 21-25$ years $(M=$ 14.61), 26 - 32 years $(M=14.68)$ and those between 33 - 38 years $(M=16.84)$. Increased age is associated with increased of mean value of IOP. 
Table 5. Multiple regression table of CCT as predictor in visual acuity and IOP.

\begin{tabular}{cccccc}
\hline $\begin{array}{c}\text { Predictor } \\
\text { variable CCT }\end{array}$ & B & SEB & B & t & $\mathrm{p}$ \\
\hline VA (decimal) & -0.03 & 0.03 & -0.11 & -0.97 & 0.33 \\
IOP (mm Hg) & -0.02 & 0.09 & -0.26 & -2.40 & 0.01 \\
\hline
\end{tabular}

B without standardization; SEB standard error.

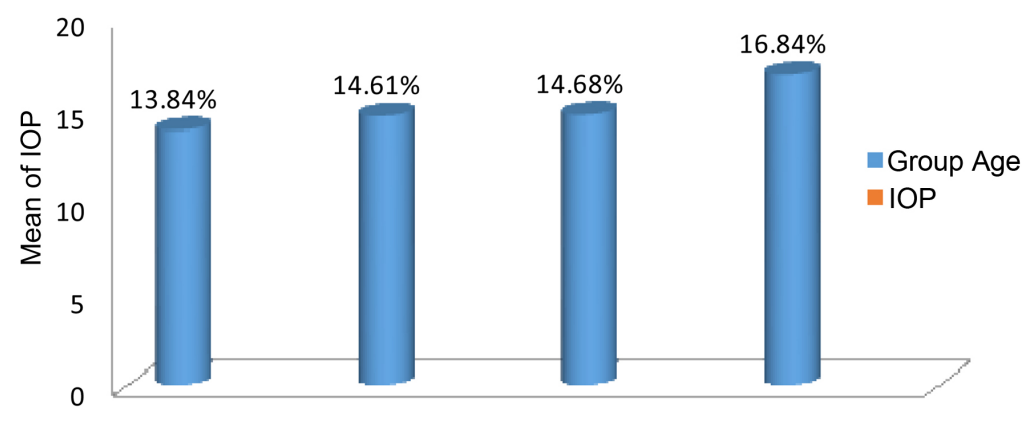

Figure 1. Differences in IOP between different age group. Differences in Intraocular presion (IOP) between different age group. 16 - 20 years have $(\mathrm{M}=$ $13.84) ; 225$ years $(\mathrm{M}=14.61) ; 26-32$ year $(\mathrm{M}=14.6) ; 33-38$ years $(\mathrm{M}=$ $16.84)$.

\section{Discussion}

The CCT seems to vary in different races. This had previously been reported by other studies as well. However, Suzuki has found a weak negative correlation between CCT and refractive error in male, but not in female (higher CCT in myopic eyes than emmetropic eyes in men [13].

Nomura also reported higher CCT values in moderate myopia than in emmetropic and hyperopic eyes; prevalence of myopia is increasing among the populations of East Asian origin [14]. With increasing rates of myopia, refractive surgery such as laser in situ keratomileusis (LASIK) has become popular in Asia. When undertaking such surgery to correct myopia, CCT is an important consideration to prevent the cornea from becoming too thin after treatment. Generally, a pachymetry value thinner than $500 \mu \mathrm{m}$ has been accepted as a cutoff value for safe refractive surgery [15].

The relationship between the CCT and refractive errors is controversial. $\mathrm{Li}$ Jinghai reported there is a negative correlation between CCT and refractive error [16]. Chang suggested there is no correlation between CCT and the type of refractive errors [17]. Central corneal thickness in myopia decreases with increasing refractive anomaly. However, Zhang Shisheng suggested there is a positive correlation between CCT and refractive error, but Liu $Z$, suggested there is no significant relationship between CCT and refractive error [18]. Bradfield reported that for every degree of increased myopic refractive error CCT is $1 \mu \mathrm{m}$ thinner than average [19]. According to Michael Mimouni, CCT is associated with the degree of myopia in adults who will undergo refractive surgery [20].

The results of our study showed that there was a negative correlation between 
respondents with myopias and the CCT $(\mathrm{r}=-0.41, \mathrm{p}=0.01)$, which means that increased CCT is associated with decrease of myopias to respondents. Meanwhile between CCT and hyperopic participants it has been found that there is no correlation $(r=0.02, p=0.91)$ as well as no correlation between CCT and emetrop participant $(\mathrm{r}=-0.22, \mathrm{p}=0.44)$.

The results showed that there was no difference in the CCT between emmetropics and refractive anomalies, rejecting our hypothesis $F(2,78)=0.09, \mathrm{p}=\mathrm{ns}$ (using One Way Anova analysis). The mean value of CCT for myopia (CCT = 547.90 , DS $=47.93)$, for hyperopia $(\mathrm{CCT}=545.21$, DS $=52.24)$ and emmetropic $(\mathrm{CCT}=550.75, \mathrm{DS}=41.29)$.

In the follow-up of the various analyses we have looked at the difference between different parameters of the eye and central corneal thickness.

According to the study by Lekskul M, greater CCT was associated with higher intraocular pressure, an increasing of intraocular pressure would increase the CCT 1.4 microm statistically significance [21]. Our results showed that there was a negative correlation between CCT and IOP $(r=-0.26, p=0.01)$. Also we have found negative correlation between the CCT and the IOP, where the increase of the CCT is associated with the decrease of IOP and vice versa .At the same time, the reported results found that CCT is a negative predictor of IOP $(\beta=-2.40$, $\mathrm{p}=0.01$ ).

Studies reported that the association between CCT and age was not significant statistically [15].

The mean CCT of the 20 - 39 years old was significantly thicker than that of the 60 - 69 years and $70-79$ years age groups. The general trend is the reduction of CCT in the older age groups. This was consistent with the studies of Wong and Hawker, who reported negative correlation between CCT and age [22] [23] [24]. From this equation, a decrease of approximately $5.0 \mu \mathrm{m}$ in CCT for every 10 -year increase in age was predicted, and this was very similar to that obtained in this study. This change in CCT with age can be attributed to changes in the structural biomechanical properties of the cornea that occur with age [24].

In our study no correlation was found between the CCT and age. In contrary with other study results due to different age group of respondents (18 - 40). According to the study conducted in eyes of Saudi, it was found that the CCT values have decreased considerably with age. So, these results are consistent with Hahn's earlier findings, which found that older subjects had lower CCT values compared to younger participants [25]. Other studies conducted at Prasad A, the age and refractive abnormalities did not affect the CCT [26].

But according to Solo T, no correlation has been found between CCT and age or sex [27].

Supported by the study by Afnan H. Alqurashi, gender differences were not significant [28]. Similarly, according to Gelawet [29], they are in conflict with some earlier findings where the average was higher in males than in females, while according to Hahn, in the oldest CCT the least apparent [26]. According to 
the study of Hashman N, they showed that males had significantly smaller skin corneas than females [30]. Also CCT did not show any gender difference, according to M. Micheal [20].

Also statistically significant relationships have not been found between the thickness of the central cornea and VA according to Lleo A [31]. Also, these results showed that there was a no correlation between CCT and VA.

In the study of Nigerian novices in order to determine the correlation between the CCT and AL, it has been found that the regression analysis show an inverse trend in the association between CCT and AL though not statistically significant [25]. There appears to be no consensus concerning the relationship between CCT and axial length. Based on the Chej MJ research, there is no relation to the relationship between CCT and axial length [32].

Meanwhile, our results showed the same-that there was no correlation between CCT and AL.

The relationship between CCT and keratometry was investigated in several earlier studies. Shimmyo and the Tajimi study reported that CCT was positively correlated with keratometry in 1976 Americans and 2868 Japanese [33] [34]. A weak correlation between CCT and keratometry was also demonstrated in Suzuki and Tong series mentioned earlier [13] [34]. In contrast, Eyesteinsson reported no correlation between CCT and keratometry values in 925 Caucasians [35]. Similar findings were also found in Chang, Fam as well as Cho and Lam's series mentioned earlier [36]. The numerous discrepancies in the research carried out are explained by various methodologies that with the decrease of the average values of the refractive error, the mean $\mathrm{KM}$ values have increased in the myopic group [1] [17]. While negative correlation was found between CCT and keratometry according to Kadhim YJ [1]. The relationship between CCT and Keratometry values has a negative correlation between CCT and Km values ( $r=$ $-0.24, \mathrm{p}=0.03$ ), which show us that CCT growth is associated with decreasing Keratometry.

\section{Acknowledgements}

To the study subjects for their co-operation.

\section{Conflicts of Interest}

The authors declare no conflicts of interest regarding the publication of this paper.

\section{Authors' Contribution}

All authors substantially contributed to this study.

\section{References}

[1] Kadhim, Y.J. and Farhood, Q.K. (2016) Central Corneal Thickness of Iraqi Population in Relation to Age, Gender, Refractive Errors, and Corneal Curvature: A Hos- 
pital-Based Cross-Sectional Study. Clinical Ophthalmology, 10, 2369-2376. https://doi.org/10.2147/OPTH.S116743

[2] Wei, W., Fan, Zh., Wang, L., Li, Zh., Jiao, W. and Li, Y. (2014) Correlation Analysis between Central Corneal Thickness and Intraocula Pressure in Juveniles in Northern China. PLoS ONE, 9, e104842. https://doi.org/10.1371/journal.pone.0104842

[3] Mashige, K.P. (2013) A Review of Corneal Diameter, Curvature and Thickness Values and Influencing Factors. South African Optometrist, 72, 185-194. https://doi.org/10.4102/aveh.v72i4.58

[4] Patwardhan, A.A., Khan, M., Mollan, S.P. and Haigh, P. (2008) The Importance of Central Corneal Thickness Measurements and Decision Making in General Ophthalmology Clinics: A Masked Observational Study. BMC Ophthalmology, 8, 1. https://doi.org/10.1186/1471-2415-8-1

[5] Boehm, A.G., Spoerl, E., et al. (2006) Effect of Central Corneal Thickness, Corneal Curvature, and Axial Length on Applanation Tonometry. Archives of Ophthalmology, 124, 471-476. https://doi.org/10.1001/archopht.124.4.471

[6] Castro, G.G., Fitt, A.D. and Sweeney, J. (2016) On the Validity of the Imbert-Fick Law: Mathematical Modelling of Eye Pressure Measurement. World Journal of Mechanics, 3, 35-51. https://doi.org/10.4236/wjm.2016.63005

[7] Sawada, A., Tomidokoro, A., Araie, M., Iwase, A. and Yamato, T. (2008) Refractive Errors in an Elderly Japanese Population: The Tajimi Study. Ophthalmology, 115, 363-370. https://doi.org/10.1016/j.ophtha.2007.03.075

[8] Das, P., Ruma Das, R., Shrivastava, P.K. and Abhisek Mondal, A. (2016) A Clinical Study on the Correlation between Axial Length, Intraocular Pressure and Central Corneal Thickness in Myopic Eyes. International Journal of Contemporary Medical Research, 3, 1141-1144.

[9] Hashemi, H., Fotouhi, A., Yekta, A., Pakzad, R., Ostadimoghaddam, H. and Khabazkhoob, M. (2018) Global and Regional Estimates of Prevalence of Refractive Errors: Systematic Review and Meta-Analysis. Journal of Current Ophthalmology, 30, 3-22. https://doi.org/10.1016/j.joco.2017.08.009

[10] Al-Ageel, S. and Al-Muammar, A.M. (2009) Comparison of Central Corneal Thickness Measurements by Pentacam, Noncontact Specular Microscope, and Ultrasound Pachymetry in Normal and Post-LASIK Eyes. Saudi Journal of Ophthalmology, 23, 181-187. https://doi.org/10.1016/j.sjopt.2009.10.002

[11] Yekta, A.A., Hashemi, H., Ostadimoghaddam, H., Shafaee, Sh., Norouzirad, R. and Khabazkhoob, M. (2013) Prevalence of Refractive Errors among the Elderly Population of Sari, Iran. Iranian Journal of Ophthalmology, 25, 123-132.

[12] Gomez-Salazar, F., Campos-Romero, A., Gomez-Campaña, H., Cruz-Zamudio, C., Chaidez-Felix, M., Leon-Sicairos, N., Velazquez-Roman, J., et al. (2017) Refractive Errors among Children, Adolescents and Adults Attending Eye Clinics in Mexico. International Journal of Ophthalmology, 5, 796-802.

[13] Suzuki, S., Suzuki, Y., Iwase, A. and Araie, M. (2005) Corneal Thickness in an Ophthalmologically Normal Japanese Population. Ophthalmology, 112, 1327-1336. https://doi.org/10.1016/j.ophtha.2005.03.022

[14] Nomura, H., Ando, F., Niino, N., Shimokata, H. and Miyake, Y. (2002) The Relationship between Age and Intraocular Pressure in a Japanese Population: The Influence of Central Corneal Thickness. Current Eye Research, 24, 81-85. https://doi.org/10.1076/ceyr.24.2.81.8161

[15] Al Mahmoud, T., Priest, D., Munger, R. and Jackson, B. (2011) Correlation between Refractive Error, Corneal Power, and Thickness in a Large Population with a Wide 
Range of Ametropia. Investigative Ophthalmology \& Visual Science, 52, 1235-1242. https://doi.org/10.1167/iovs.10-5449

[16] Li, J.H., Zhou, F. and Zhou, S.A. (1994) Research on Corneal Thickness at Multi-Points in Normal and Myopic Eyes. Chinese Journal of Ophthalmology, 30, 445-448.

[17] Chang, S.W., Tsai, I.L., Hu, F.R., Lin, L.L. and Shih, Y.F. (2001) The Cornea in Young Myopic Adults. British Journal of Ophthalmology, 85, 916-920.

[18] Liu, Z. and Pflugfelder, S.C. (2000) The Effects of Long-Term Contact Lens Wear on Corneal Thickness, Curvature, and Surface Regularity. American Academy of Ophthalmology, 107, 105-111. https://doi.org/10.1016/S0161-6420(99)00027-5

[19] Bradfield, Y.S., Melia, B.M., Repka, M.X., Kaminski, B.M., Davitt, B.V., et al. (2011) Central Corneal Thickness in Children. Archives of Ophthalmology, 129, 1132-1138. https://doi.org/10.1016/j.jaapos.2011.01.011

[20] Mimouni, M., Flores, V., Shapira, Y., Graff, Sh., Levartovsky, Sh., Sela, T., Munzer, G. and Kaiserman, I. (2018) Correlation between Central Corneal Thickness and Myopia 2017. International Ophthalmology, 38, 2547-2551. https://doi.org/10.1007/s10792-017-0766-1

[21] Lekskul, M., Aimpun, P., Nawanopparatskul, B., Bumrungsawat, S., Trakulmungkijkarn, T., Charoenvanichvisit, J., Herunpattarawong, T., Suksangthong, P., Jaiprasat, T., Rattananantapat, M. and Sudprasert, T. (2005) The Correlations between Central Corneal Thickness and Age, Gender, Intraocular Pressure and Refractive Error of Aged 12-60 Years Old in Rural Thai Community. Journal of the Medical Association of Thailand, 88, S175-S179.

[22] Wong, A.C., Wong, C., Yuen, N.S. and Hui, S.P. (2002) Correlational Study of Central Corneal Thickness Measurements on Hong Kong Chinese Using Optical Coherence Tomography, Orbscan and Ultresound Pachymetry. Eye, 16, 715-721. https://doi.org/10.1038/sj.eye.6700211

[23] Hawker, M.J., Edmunds, M.R., Vernon, S.A., Hillman, J.G. and MacNab, H.K. (2009) The Relationship between Central Corneal Thickness and Optic Disc in an Elderly Population: The Bridlington Eye Assessment Project. Eye, 23, 56-62.

https://doi.org/10.1038/sj.eye.6703001

[24] Iyamu, E. and Osuobeni, E. (2012) Age, Gender, Corneal Diameter, Corneal Curvature and Central Thickness in Nigerians with Normal Intra Ocular Pressure. Journal Optometry, 5, 87-97. https://doi.org/10.1016/j.optom.2012.02.001

[25] Hahn, S., Azen, S., Lai, M.Y. and Varma, R. (2003) Central Corneal Thickness in Latinos. Investigative Ophthalmology \& Visual Science, 44, 1508-1512.

[26] Prasad, A., Fry, K. and Hersh, P. (2011) Relationship of Age and Refraction to Central Corneal Thickness. Cornea, 30, 553-555.

https://doi.org/10.1097/ICO.0b013e3181fb880c

[27] Solu, T., Baravaliya, P., Patel, I., Kamble, S., Savaliya, C. and Golakiya, B. (2016) Correlation of Central Corneal Thickness and Axial Length in Myopes, Emmetropes, and Hypermetropes. International Journal of Scientific Study, 3, 206-209.

[28] Alqurashi, A.H., Afifi, O.K., Jabr, H.F. and Aljuaid, H.A. (2018) A Comparative Study of Central Corneal Thickness, Mean Keratometry and Astigmatism in Persons with and without Refractive Errors in Taif. International Journal of Community Medicine and Public Health, 5, 416-421. https://doi.org/10.18203/2394-6040.ijcmph20175932

[29] Gelaw, Y., Kollmann, M., Irungu, N. and Ilako, R. (2010) The Influence of Central Corneal Thickness on Intraocular Pressure Measured by Goldmann Applanation 
Tonometry among Selected Ethiopian Communities. Journal of Glaucoma, 19, 514-518. https://doi.org/10.1097/IJG.0b013e3181ca7708

[30] Hashmani, N., Hashmani, S., Hanfi, A.N., Ayub, M., Saad, S.M., Rajani, H., Muhammad, M.G. and Aziz, M. (2017) Effect of Age, Sex, and Refractive Errors on Central Corneal Thickness Measured by Oculus Pentacam. Clinical Ophthalmology, 11, 1233-1238.

[31] Lleó, A., Marcos, A., Calatayud, M., Alonso, L., Rahhal, S.M. and Sanchis-Gimeno, J.A. (2003) The Relationship between Central Corneal Thickness and Goldmann Applanation Tonometry. Clinical and Experimental Optometry, 86, 104-108. https://doi.org/10.1111/j.1444-0938.2003.tb03068.x

[32] Chen, M.J., Liu, Y.T., Chen, Y.C., Chou, C.K. and Lee, S.M. (2009) Relationship between Central Corneal Thickness, Refractive Error, Corneal Curvature, Anterior Chamber Depth and Axial Length. Journal of the Chinese Medical Association, 72, 133-137. https://doi.org/10.1016/S1726-4901(09)70038-3

[33] Shimmyo, M., Ross, A.J., Moy, A.J. and Mostafavi, B. (2003) Intraocular Pressure, Goldmann Applanation Tension, Cornea Thickness, and Corneal Curvature in Caucasians, Asians, Hispanics, and African Americans. American Journal of Ophthalmology, 136, 603-613. https://doi.org/10.1016/S0002-9394(03)00424-0

[34] Tong, L., Saw, S.M., Siak, J.K., Gazzard, G. and Tan, D. (2004) Corneal Thickness Determination and Correlates in Singaporean Schoolchildren. Investigative Ophthalmology \& Visual Science, 45, 4004-4009. https://doi.org/10.1167/iovs.04-0121

[35] Eyesteinsson, T., Jonasson, F., Sasaki, H., Arnarsson, A., Sverrisson, T., Sasaki, K., Stefánsson, E., et al. (2002) Central Corneal Thickness, Radius of the Corneal Curvature and Intraocular Pressure in Normal Subjects Using Non-Contact Techniques. Acta Ophthalmologica Scandinavica, 80, 11-15. https://doi.org/10.1034/j.1600-0420.2002.800103.x

[36] Cho, P. and Lam, C. (1999) Factors Affecting the Central Corneal Thickness of Hong Kong Chinese. Current Eye Research, 18, 368-374. https://doi.org/10.1076/ceyr.18.5.368.5347 